ISSN: $2576-2141$

\title{
Drug Trafficking on Darkmarkets: How Cryptomarkets are Changing Drug Global Trade and the Role of Organized Crime
}

\author{
Federico Bertola ${ }^{1}$ \\ Catholic University of Milan, Italy
}

\begin{abstract}
Drug trafficking on darknet based marketplaces has become a highly concerning topic in law enforcement activities, recently. Even though Darkmarkets represent only a tiny fraction of the global drug trade, they are changing the drug markets social networks, introducing a new paradigm of the link between vendors and buyers of drugs. The aim of this study is to critically review the darkmarkets' ecosystem and the previous literature regarding these new marketplaces, trying to investigate how the drug trade is changing with these new technologies, and the role of organised crime $(O C)$ in these new illegal markets. And trying to understand how and whether is it involved $O C$ on these cyber drug markets and the chain behind them. Despite opinions of part of the academy, the results show that there are no empirical evidences of direct involvement of $O C$ as vendors in darkmarkets. However, there are evidences of an indirect role of $O C$ in darknet drug trafficking, as supplier of illegal drugs to the online-vendors.
\end{abstract}

KEYWORDS: Drug Trafficking, Darkmarkets, Organised Crime, Cyber Crime, Online Drug Markets.

\section{Introduction}

A darkmarket, or cryptomarket, is a darknet-based platform that propose a wide range of illicit goods and services with a predominancy of illicit drugs proposals of sale (Aldridge \& Décary-Hétu, 2016; Martin, 2014). The proliferation of darknet (a small part of the Deep Web) based marketplaces of drugs within contemporary cyber drug markets is a factor of increasing public opinion and law enforcement concern. Online drug communities are increasingly innovative in their capacities to sale drugs, providing information for users about drug quality and providing advices around optimal use (Barratt, 2012; Broséus et al., 2016).

The widespread diffusion of new Darkmarkets, has been enabled by the combination of payments through cryptocurrencies that are scarcely traceable (e.g. Bitcoin or Monero), The Onion Router (TOR) network, and the encryption of private messages (Dordal, 2018; Martin, 2014; Me \& Pesticcio, 2018). Due to these anonymizing factors, on darknet markets, vendors and buyers can safely trade unlawful goods and commodities, with profoundly mitigating risks.

This paper aims to critically review the darkmarkets' ecosystem and the previous literature regarding these new marketplaces, trying to investigate how the drug trade is changing with these new technologies, and the role of organised crime, trying to understand how and whether is it involved OC on these cyber drug markets and within the chain behind them.

\footnotetext{
${ }^{1}$ E-mail: federico.bertola03@icatt.it
} 


\section{Method}

This study employed direct observation of principal international darkmarkets platforms, including "Berlusconi Market", "Silk Road 2.0", "Silk Road 3.0", "AlphaBay", "Hansa Market". In addition, previous literature statements and data gathering were used to conduct the research (Aldridge \& Décary-Hétu, 2016; Leukfeldt et al., 2017; Soska \& Christin, 2015). Open Source data of law enforcement operations against darkmarkets were used in order to analyze the specific characteristics of vendors, buyers and networks of cryptomarkets (Europol, 2015; U.S. Immigration and Customs Enforcement, 2016). Furthermore, the research employed face to face interviews with European law enforcement analysts.

\section{Darkmarkets ecosystem}

Darknet markets, cryptomarkets or darkweb-based marketplace consist of websites, which are similar to online platforms that facilitate trade, such as eBay or Amazon (Barratt, 2012). The reliance on encryption technology and anonymization differentiates cryptomarkets from others online platforms (Martin, 2013). These technologies, combined with a user-friendly interface, allow illicit trades to take place in easy-to-use platforms without any direct meeting and with identities and locations anonymized, making darkmarkets a fertile ground for illicit trades, creating several problems to law enforcement agencies investigation (Bakken et al., 2017; Tzanetakis, 2018). The first darknet market of notoriety was Silk Road, in operation from January 2011 and sized by the US Federal Bureau of Investigation (FBI) in October 2013 (European Commission \& Europol, 2017; Martin, 2013). Silk Road 2.0 was launched soon after the seizure of Silk Road, and since that time there has been a proliferation of darknet markets, with an estimation of over 100 marketplaces having emerged to date (European Commission \& Europol, 2017).

Considering their life on the dark side of the web, most of enduring markets, such as Valhalla, Dream Market and Outlaw Market operated for a mean of just under four years; the majority remained active for just over eight months and marketplaces such as AlphaBay, Silk Road 3.0 and Silk Road lasted for between one and two years (European Commission \& Europol, 2017). From January 2019 the most important Dark Market was Berlusconi Market, with more than 100.000 announcement of illegal goods (Guardia di Finanza, 2019). Italian Economic Law Enforcement force, Guardia di Finanza, in November 2019 arrested three administrators of Berlusconi Market, making It no more longer operational (Guardia di Finanza, 2019). This is the fourth case of putting down a Black Market from law Enforcement, after the operations of FBI and Dutch Police versus "Silk Road", "Alpha Bay", "Hansa Market" (Europol, 2015; FBI, 2015a, 2015b).

The collaboration and information sharing between international law enforcement agencies is clearly crucial to mount an effective response to the exponential growth of darknet markets (Reitano et al., 2015).

As evidenced, law enforcement operations are based on take-downs of illegal online markets; however, the result of these operations has been outlined by several studies that generate only the displacement of vendors and buyers to alternative online markets, resulting not very effective measures to affect the volume of sales on darknet (Décary-Hétu \& Giommoni, 2017; Soska \& Christin, 2015). Different approaches to face darkmarket's trade can be focused on targeting reputation system and feedbacks of online traders, destabilizing their activities mining their credibility (Décary-Hétu \& Giommoni, 2017; Soska \& Christin, 2015). 


\section{Drug trafficking on Darkmarkets}

The trade in illicit drugs is the stronghold of most of Darknet markets: most of the activities on darkmarkets is drug related (Europol, 2017; Me \& Pesticcio, 2018). It is estimated that $57 \%$ of Dark markets listings offer drugs (Soska \& Christin, 2015; World Drug Report 2018 , n.d.). In spite of their proliferation and exponential growth (Aldridge \& Dècary-Hètu, 2016; Aldridge \& Décary-Hétu, 2016), Darkmarkets represent only a tiny fraction of the global drugs trade (Aldridge \& Dècary-Hètu, 2016). However, drug cryptomarkets represent a new form of trafficking: they have the potential to transform local offline markets for illegal drugs by providing a new channel for drug flow across locales (Aldridge \& Décary-Hétu, 2016). There is a growing view among researchers that decentralized networks now provide the bulk of various drug markets (Dorn et al., 1992; Heber, 2009; Malm \& Bichler, 2011; Martin, 2013): this view radically contrast with earliest models of drug distribution, where centralized and hierarchical Organized Crime (OC) groups were considered, often mistakenly, to have played this central function (Edwards \& Levi, 2008; Kenney, 2007). In this context, for instance, SilkRoad and the others darkmarkets, functions under a direct distribution model: there is no necessity for the involvement of drug traffickers, brokers, wholesalers, street retailers or other intermediary (Christin, 2013; Hout \& Bingham, 2013; Martin, 2013). Drugs can simply be posted online directly from producers to consumers, without the necessity for personal contacts or interactions between the parties (Aldridge \& Dècary-Hètu, 2016; Aldridge \& Décary-Hétu, 2014b; Martin, 2013).

The reduced number of intermediaries and involved parties generate more efficient operation of the network, meaning fewer price increases and less necessity for product adulteration (Martin, 2013). In addition, darkmarkets have regulatory mechanisms such as Escrow, seller and buyer trust metrics, marketplace adjudication of disputes (Christin, 2013), that remove part of the instability of illegal markets that usually generate conflict and violence (Aldridge \& Dècary-Hètu, 2016; Aldridge \& Décary-Hétu, 2014b, 2016; Heber, 2009; Martin, 2014).

\section{Buyers and vendors characteristics}

Previous research has investigated information on those purchasing drugs through darknet markets: from the analysis of Silk Road users, they found that most of them were male, with an history of drug use (Barratt et al., 2014; Hout \& Bingham, 2013). Looking for motives for buying drugs on the darknet, studies highlighted that people decided to buy drugs from Silk Road because it offered a wider range of drugs, better quality and greater convenience than was usually available offline (Barratt et al., 2014). Additionally, it has been found that darkmarkets are attractive to buyers that perceive them as safer environment in which to buy drugs because of the absence of personal contact with dealers, deleting all sorts of risk of potential violence (Barratt \& Maddox, 2016; Martin, 2013). However, while the risks of direct contact with drug vendors may be removed on darkmarkets, there are some other risks involved in buying from darknet markets: for instance, while the seller's location remains anonymous in web-based drug transactions, a delivery address is required for the buyer: this may leave to the risk of "doxing" - the practice of publishing personal information about an individual - or it can augment the probability to be exposed to the risk of fraud and blackmail, as well as being identified by law enforcement (Aldridge \& Décary-Hétu, 2016; European Commission \& Europol, 2017).

As mentioned before, darkmarkets provide the possibilities for drug dealers to extend their customer base outside their controlled physical area, an extension that would not have been possible in physical world because of rivalry with others drug dealers (Morselli et al., 2011). 
Drug vendors operating on these markets are able to interact with unknown customers, with the trust given by the anonymity mechanisms built in to the marketplace (Martin, 2014), but even from the feedback left by previous customers. In fact, vendors can openly advertise their products for sale to any user of the marketplace across the globe, even earning online 'reputation' scores from the diverse feedback and reviews left by previous buyers (Aldridge \& Décary-Hétu, 2016). Previous studies refers that the top 1\% most successful vendors are responsible for 51.5\% of all transactions on Darknet markets (Soska \& Christin, 2015).

\section{Organised crime role on Drug Trafficking on Darkmarkets}

As analysed before, darkmarkets-based drug distribution presently accounts for a tiny, but steadily growing share of the global trade in illegal drugs (Christin, 2013; Martin, 2013). Silk Road and the other darknet marketplaces have the potential to transform traditional drug distribution network, with long-term implications for the global drugs industry (Martin, 2013). In fact, more direct web-based distribution networks between drug consumers and producers may significantly restrain the involvement of narco-traffickers, Organised Crime and streetlevel gangs in global and local drug distribution (Martin, 2013).

According to previous statements, it would seem that Organised Crime is excluded from the landscape of darkmarkets business, because producers directly contact people. There are different opinions regarding the involvement of Organised Crime in drug distribution in darkweb. According to the Europol' s report about "How illegal drugs sustain Organised Crime in the EU": on darkmarkets "While it is assessed that the majority of vendors are lone offenders, dealing in small amount, it is reported that many of the 'top sellers' are likely organised crime groups earning significant profits " (Europol, 2017, p. 9). However, according to some others researchers and institutions, even if existing literature suggests that it is likely that the criminogenic characteristics of cyberspace are attractive to OC (Broadhurst et al., 2014; Choo $\&$ Smith, 2008; Europol, 2017), undeniable proof of the presence of OC online is so far missing (Lavorgna, 2018; Leukfeldt et al., 2017; McCusker, 2006; RC Van der Hulst, 2008).

Organised Crime is often accused of as being used as "a catchphrase to express the growing anxieties" on the growth of illicit markets (Leukfeldt et al., 2017; Paoli, 2002). Therefore, it would seem that the alleged link between cyberspace and OC lacks of sufficient empirical evidences, and that seems to be more part of a process of "moral panic" (Lavorgna, 2018; Lusthaus, 2013)

As evidenced, Darknet markets are locate into the global illicit supply chain: they provide a novel form of retail distribution, having an impact on the last mile of the supply chain, leaving existing trafficking routes intact (Dittus et al., 2018; Duxbury \& Haynie, 2018; Weber \& Kruisbergen, 2019).

In conclusion, it is not clear the direct role of OC on darkmarkets, it is not even clear if there are vendors directly related or associated to $\mathrm{OC}$, however it is important to consider that Mafias often works at the level of "supplier" of drugs, providing the link between international drug markets and local sellers, and often rely on diverse supply chains and a plurality of retailers (Dorn et al., 1992; Paoli, 2004), even in darkweb. Therefore, even though OC may not be directly involved in drug trafficking on darkmarkets, there are evidences that organised criminals act as providers for vendors (Weber \& Kruisbergen, 2019).

\section{Conclusions}

It is undeniable that the size of the Darkmarkets analysed were negligible in comparison to the overall international drug trade: for instance, revenues on Silk Road were calculated in tens of millions of dollars whereas the international drug trade is measured in hundreds of billions of dollars (Aldridge \& Décary-Hétu, 2014b; Thoumi, 2005). However, the importance 
of the scalability and exponential growth of darkmarkets not stem from the revenues it has generated, but rather from the impact it is likely to have on how drugs are bought and sold in the future (Aldridge \& Décary-Hétu, 2014b). There is a strong possibility of being in front a potential and actual transformative criminal innovation. As previously analyzed these markets are not immune from the presence of OC, especially thinking about the chain of illegal smuggling: the wholesalers of drugs are usually part or strictly affiliate to OC (Dorn et al., 1992; Heber, 2009; Paoli, 2004). There is a strong possibility that the lower level of drug distribution networks may use darkmarkets to streamline their activities and reduce their risk of arrests (Martin, 2014). This process can potentially change how drug markets operate in a way that may set back regulation efforts by decades, such as computers have changed the way we manage and consume information (Aldridge \& Décary-Hétu, 2014; European Commission \& Europol, 2017; Martin, 2014).

It is undeniable that Law enforcement and policy makers should think about different strategies, instead of crackdowns, in order to face the problem of illegal online drug trafficking. Different approaches to face darkmarket trade can be focused on targeting reputation system and feedbacks of online traders, obtaining the destabilization of illicit activities by mining vendors' credibility (Décary-Hétu \& Giommoni, 2017; Soska \& Christin, 2015); furthermore, agencies should focus their efforts on targeting the small fraction of vendors responsible for most of sales, forcing buyers to find new suppliers and to build up trust again with them (Décary-Hétu \& Giommoni, 2017; Soska \& Christin, 2015).

In conclusion, darkmarkets are rapidly growing and their threats are exponentially growing with them. It is therefore a task of no small priority for criminologists, academia, law enforcements and intelligence agencies to conduct further research on these new forms of trafficking and try to elaborate effective strategies of contrast, in order to shine a light into the deeper recesses of the darknet.

\section{References}

Aldridge, J., \& Décary-Hétu, D. (2014a). Not an 'Ebay for Drugs': The Cryptomarket 'Silk Road' as a Paradigm Shifting Criminal Innovation. SSRN Electronic Journal. https://doi.org/Aldridge, Judith and Décary-Hétu, David, Not an 'Ebay for Drugs': The Cryptomarket 'Silk Road' as a Paradigm Shifting Criminal Innovation (May 13, 2014). Available at SSRN $\quad$ https://ssrn.com/abstract=2436643 or http://dx.doi.org/10.2139/ssrn.2436643

Aldridge, J., \& Dècary-Hètu, D. (2016). Cryptomarkets and the future of illicit drug markets. In The internet and drug markets (pp. 23-30). EMCDDA, Publication Office of the European Union. https://doi.org/10.2810/324608

Aldridge, J., \& Décary-Hétu, D. (2016). Hidden wholesale: The drug diffusing capacity of online drug cryptomarkets. International Journal of Drug Policy, 35, 7-15. https://doi.org/10.1016/j.drugpo.2016.04.020

Bakken, S. A., Moeller, K., \& Sandberg, S. (2017). Coordination problems in cryptomarkets: Changes in cooperation, competition and valuation: European Journal of Criminology. https://doi.org/10.1177/1477370817749177

Barratt, M. (2012). Silk Road: Ebay for drugs. Addiction (Abingdon, England), 107, 683. https://doi.org/10.1111/j.1360-0443.2011.03709.x

Barratt, M. J., Ferris, J. A., \& Winstock, A. R. (2014). Use of Silk Road, the online drug marketplace, in the United Kingdom, Australia and the United States. Addiction (Abingdon, England), 109(5), 774-783. https://doi.org/10.1111/add.12470

Barratt, M. J., \& Maddox, A. (2016). Active engagement with stigmatised communities through digital ethnography. Qualitative Research, 16(6), 701-719. https://doi.org/10.1177/1468794116648766 
Broadhurst, R., Grabosky, P., Alazab, M., \& Chon, S. (2014). Organizations and cyber crime: An analysis of the nature of groups engaged in cyber crime. International Journal of Cyber Criminology, 8(1), 1-20.

Broséus, J., Rhumorbarbe, D., Mireault, C., Ouellette, V., Crispino, F., \& Décary-Hétu, D. (2016). Studying illicit drug trafficking on Darknet markets: Structure and organisation from a Canadian perspective. Forensic Science International, 264, 7-14. https://doi.org/10.1016/j.forsciint.2016.02.045

Choo, K.-K. R., \& Smith, R. (2008). Criminal Exploitation of Online Systems by Organised Crime Groups. Asian Journal of Criminology, 3, 37-59. https://doi.org/10.1007/s11417-007-9035-y

Christin, N. (2013). Traveling the silk road: A measurement analysis of a large anonymous online marketplace. Proceedings of the 22nd International Conference on World Wide Web - WWW'13, 213-224. https://doi.org/10.1145/2488388.2488408

Décary-Hétu, D., \& Giommoni, L. (2017). Do police crackdowns disrupt drug cryptomarkets? A longitudinal analysis of the effects of Operation Onymous. Crime, Law and Social Change, 67(1), 55-75. https://doi.org/10.1007/s10611-016-9644-4

Dittus, M., Wright, J., \& Graham, M. (2018). Platform criminalism: The last-mile geography of the darknet market supply chain. 277-286.

Dordal, P. L. (2018). The Dark Web. In H. Jahankhani (Ed.), Cyber Criminology (pp. 95-117). Springer International Publishing. https://doi.org/10.1007/978-3-319-97181-0_5

Dorn, N., Murji, K., \& South, N. (1992). Traffickers: Drug Markets and Law Enforcement. Routledge. http://www.routledge.com/books/details/9780415035378/

Duxbury, S. W., \& Haynie, D. L. (2018). Building them up, breaking them down: Topology, vendor selection patterns, and a digital drug market's robustness to disruption. Social Networks, 52, 238-250. https://doi.org/10.1016/j.socnet.2017.09.002

Edwards, A., \& Levi, M. (2008). Researching the organization of serious crimes. Criminology \& Criminal Justice, 8(4), 363-388. https://doi.org/10.1177/1748895808097403

European Commission \& Europol (Eds.). (2017). Drugs and the darknet: Perspectives for enforcement, research and policy. Publications Office of the European Union.

Europol. (2015, November 20). Massive blow to criminal Dark Web activities after globally coordinated operation Europol.

https://www.europol.europa.eu/newsroom/news/massive-blow-to-criminal-dark-webactivities-after-globally-coordinated-operation

Europol. (2017, December 6). How Illegal Drugs Sustain Organised Crime in the EU. Europol. https://www.europol.europa.eu/publications-documents/how-illegal-drugs-sustainorganised-crime-in-eu

FBI. (2015a). Ross Ulbricht, the Creator and Owner of the Silk Road Website, Found Guilty in Manhattan Federal Court on All Counts-FBI. https://www.fbi.gov/contact-us/fieldoffices/newyork/news/press-releases/ross-ulbricht-the-creator-and-owner-of-the-silkroad-website-found-guilty-in-manhattan-federal-court-on-all-counts

FBI. (2015b, November 20). AlphaBay Takedown-FBI. https://www.fbi.gov/news/stories/alphabay-takedown

Guardia di Finanza. (2019, November 7). Arrestati tre amministratori del black market denominato berlusconi market, attivo nel dark web. Guardia Di Finanza. http://www.gdf.gov.it/stampa/ultime-notizie/anno-2019/novembre/arrestati-treamministratori-del-black-market-denominato-berlusconi-market-attivo-nel-dark-web

Heber, A. (2009). The networks of drug offenders. Trends in Organized Crime, 12, 1-20. https://doi.org/10.1007/s12117-008-9055-8

Hout, M. C. V., \& Bingham, T. (2013). 'Surfing the Silk Road': A study of users' experiences. International Journal of Drug Policy, 24(6), 524-529. https://doi.org/10.1016/j.drugpo.2013.08.011 
Kenney, M. (2007). The Architecture of Drug Trafficking: Network Forms of Organisation in the Colombian Cocaine Trade. Global Crime, 8(3), 233-259. https://doi.org/10.1080/17440570701507794

Lavorgna, A. (2018). Cyber-organised crime. A case of moral panic? Trends in Organized Crime. https://doi.org/10.1007/s12117-018-9342-y

Leukfeldt, E. R., Lavorgna, A., \& Kleemans, E. R. (2017). Organised cybercrime or cybercrime that is organised? An assessment of financial cybercrime as organised crime. European Journal on Criminal Policy and Research, 23(3), 287-300. https://doi.org/10.1007/s10610-016-9332-z

Lusthaus, J. (2013). How organised is organised cybercrime? Global Crime, 14(1), 52-60. https://doi.org/10.1080/17440572.2012.759508

Malm, A., \& Bichler, G. (2011). Networks of Collaborating Criminals: Assessing the Structural Vulnerability of Drug Markets. Journal of Research in Crime and Delinquency, 48(2), 271-297. https://doi.org/10.1177/0022427810391535

Martin, J. (2013). Lost on the Silk Road: Online drug distribution and the 'cryptomarket'. Criminology and Criminal Justice, 14, 351-367. https://doi.org/10.1177/1748895813505234

Martin, J. (2014). Drugs on the Dark Net: How Cryptomarkets are Transforming the Global Trade in Illicit Drugs. https://doi.org/10.1057/9781137399052

McCusker, R. (2006). Transnational organised cyber crime: Distinguishing threat from reality. Crime, Law and Social Change, 46(4), 257-273. https://doi.org/10.1007/s10611-0079059-3

Me, G., \& Pesticcio, L. (2018). Tor Black Markets: Economics, Characterization and Investigation Technique. In H. Jahankhani (Ed.), Cyber Criminology (pp. 119-140). Springer International Publishing. https://doi.org/10.1007/978-3-319-97181-0_6

Morselli, C., Turcotte, M., \& Tenti, V. (2011). The mobility of criminal groups. Global Crime, 12, 165-188. https://doi.org/10.1080/17440572.2011.589593

Paoli, L. (2002). The paradoxes of organized crime. Crime, Law and Social Change, 37(1), 5197. https://doi.org/10.1023/A:1013355122531

Paoli, L. (2004). The Illegal Drugs Market. Journal of Modern Italian Studies, v.9, 188-208 (2004), 9. https://doi.org/10.1080/13545710410001679466

RC Van der Hulst. (2008). Sociale netwerkanalyse en de bestrijding van criminaliteit en terrorisme. Justitiële Verkenningen, 3-20.

Reitano, T., Oerting, T., \& Hunters, M. (2015). Innovations in International Cooperation to Counter Cybercrime. The European Review of Organised Crime. https://globalinitiative.net/innovations-in-international-cooperation-to-countercybercrime/

Ross Ulbricht, the Creator and Owner of the Silk Road Website, Found Guilty in Manhattan Federal Court on All Counts-FBI. (n.d.). Retrieved 6 December 2019, from https://www.fbi.gov/contact-us/field-offices/newyork/news/press-releases/rossulbricht-the-creator-and-owner-of-the-silk-road-website-found-guilty-in-manhattanfederal-court-on-all-counts

Soska, K., \& Christin, N. (2015). Measuring the Longitudinal Evolution of the Online Anonymous Marketplace Ecosystem. 33-48. https://www.usenix.org/node/190887

Thoumi, F. E. (2005). The Colombian Competitive Advantage in Illegal Drugs: The Role of Policies and Institutional Changes. Journal of Drug Issues, 35(1), 7-26. https://doi.org/10.1177/002204260503500101

Tzanetakis, M. (2018). Comparing cryptomarkets for drugs. A characterisation of sellers and buyers over time. International Journal of Drug Policy, 56, 176-186. https://doi.org/10.1016/j.drugpo.2018.01.022 
U.S. Immigration and Customs Enforcement. (2016, October 31). Law enforcement agencies around the world collaborate on international Darknet marketplace enforcement operation. U.S. Immigration and Customs Enforcement. https://www.ice.gov/news/releases/law-enforcement-agencies-around-worldcollaborate-international-darknet-marketplace

Weber, J., \& Kruisbergen, E. W. (2019). Criminal markets: The dark web, money laundering and counterstrategies - An overview of the 10th Research Conference on Organized Crime. Trends in Organized Crime. https://doi.org/10.1007/s12117-019-09365-8

World Drug Report 2018. (n.d.). Retrieved 1 December 2019, from https://www.unodc.org/wdr2018/

Manuscript received January 30, 2020

Final revision received April 27, 2020

Accepted April 30, 2020 